\title{
Estudos sobre unidades de conservação: um levantamento em periódicos brasileiros
}

\section{RESUMO}

Marcelo Borges Rocha rochamarcelo36@yahoo.com.br Centro Federal de Educação

Tecnológica Celso Suckow da Fonseca - CEFET/RJ

Mylena Guedes Passeri mylena.passeri@gmail.com Centro Federal de Educação Tecnológica Celso Suckow da Fonseca - CEFET/RJ

Stefano Bruno Vieira Gomes stefanogomes@msn.com Centro Federal de Educação Tecnológica Celso Suckow da Fonseca - CEFET/RJ

Rafael Oliveira Rocha rocha.rafael1000@gmail.com Centro Federal de Educação Tecnológica Celso Suckow da Fonseca - CEFET/R

\begin{abstract}
Unidades de Conservação são importantes espaços naturais protegidos que auxiliam na preservação dos ambientes e se destacam como locais não formais propícios para estratégias de Educação Ambiental. Neste estudo, investigou-se artigos publicados em revistas brasileiras classificadas como $A 1$ ou $A 2$ pela CAPES, na área de Ensino, visando contribuir para o entendimento do estado da arte sobre o tema. A amostra estudada foi de dezesseis artigos. Observou-se com destaque vínculos institucionais na esfera pública. A região Sudeste predomina em quantidade de publicações e a baixa expressividade das demais regiões é preocupante. O perfil de preferência investigativa foi o de estudantes e moradores do entorno. Destaca-se certa carência de parcerias institucionais e da esfera privada nos estudos investigados. Considerando a importância de se preservar o meio ambiente, espera-se que mais estudos e ações possam contribuir para o entendimento e resolução das lacunas apontadas neste trabalho.
\end{abstract}

PALAVRAS-CHAVE: Unidades de Conservação. Educação Ambiental. Biodiversidade. 
As Unidades de Conservação (UC's), áreas protegidas instituídas pelo Poder Público, apresentam dentre suas funções a de conservação e preservação da biodiversidade presente em um ambiente natural (BENSUSAN, 2006). Estas áreas são protegidas por lei e possuem relevante interesse ecológico, pois os territórios que as constituem podem relacionar-se com a preservação de ambientes altamente vulneráveis e sensíveis aos impactos antrópicos, como também desenvolver a sustentabilidade de comunidades tradicionais. De acordo com o Sistema Nacional de Unidades de Conservação (SNUC), conjunto de diretrizes e procedimentos que orientam a implantação e gestão dessas áreas, uma UC pode ser definida como (BRASIL, 2000):

Espaço territorial e seus recursos ambientais, incluindo as águas
jurisdicionais, com características naturais relevantes, legalmente
instituído pelo Poder Público, com objetivos de conservação e
limites definidos, sob regime especial de administração, ao qual se
aplicam garantias adequadas de proteção.

As UC's podem ser divididas em duas categorias: áreas de proteção integral e de uso sustentável. A primeira é caracterizada por permitir o uso dos recursos naturais de forma indireta, enquanto a segunda permite o uso destes recursos de forma direta, desde que fiscalizado pelo Poder Público, garantindo o uso responsável dessas áreas (MACIEL, 2012). A importância das UC's para a manutenção da biodiversidade é bastante relevante, visto que nas regiões onde elas não existem há uma exposição maior a práticas antrópicas irresponsáveis e danosas ao ambiente.

Assim, entende-se que a demarcação das UC's é uma estratégia extremamente importante para a conservação e preservação dos ecossistemas e biomas, em especial, ambientes de alta biodiversidade e riqueza, tais como encontramos em muitas regiões brasileiras (TABARELLI et al., 2005).

Ressalta-se a presença de dois biomas exclusivos do Brasil e com alta importância de preservação: a Mata Atlântica e o Cerrado. A Mata Atlântica apresenta a maior biodiversidade do planeta, contando com 20.000 espécies de vegetais distribuídos por cerca de $1.300 .000 \mathrm{~km}^{2}$ em 17 estados do território brasileiro, caracterizando-se como a quinta área mais rica em espécies endêmicas do mundo.

De acordo com Cunha e Guedes (2013), a Mata Atlântica apresenta ainda importante relevância para o ciclo hídrico e a disponibilidade de água para a população, pois compreende oito bacias hidrográficas (responsáveis pelo abastecimento de $70 \%$ da população). Além disso, a presença da Mata influencia a umidade atmosférica da região, na proteção do solo contra a erosão, auxilia na diminuição do gás carbônico e reduz a possibilidade de ilhas de calor em certos locais, assim, impactando diretamente na qualidade de vida da população.

Dados do Instituto Brasileiro de Geografia e Estatística (IBGE, 2004), apontam que o Cerrado ocupa um quarto do território brasileiro, uma área de 204,7 milhões de hectares na região central brasileira. A região apresenta um solo produtivo com plantações diversas. É considerada a savana mais rica do 
mundo, apresentando cerca de $5 \%$ da biodiversidade do planeta e $44 \%$ da sua flora é endêmica (KLINK e MACHADO, 2005).

Apesar disso, esses biomas encontram-se altamente degradados e com diversas espécies ameaçadas de extinção. Portanto, é imprescindível que em um país tão rico em biodiversidade como o Brasil, a criação, a gestão e o uso de UC's sejam temas bastante estudados e debatidos, de forma que possamos ratificar os benefícios da preservação do ambiente.

Nesse sentido, estudos relacionados às UC's e aos impactos antrópicos no ambiente podem contribuir para minimizar a situação de degradação dos ecossistemas por se constituírem fonte de informações e fundamentos para projetos de educação e sensibilização ambiental. Com o aumento de interesse por parte da sociedade, aumenta-se a possibilidade de mais instituições de fomento financiarem estudos e projetos que abordem as UC's como fator principal de pesquisa.

Uma das áreas de estudos e ações importantes neste contexto é a Educação Ambiental (EA). De acordo com o artigo primeiro da Política Nacional de Educação Ambiental (BRASIL, 1999):

\section{Entendem-se por educação ambiental os processos por meio dos quais o indivíduo e a coletividade constroem valores sociais, conhecimentos, habilidades, atitudes e competências voltadas para a conservação do meio ambiente, bem de uso comum do povo, essencial à sadia qualidade de vida e sua sustentabilidade.}

Estratégias de EA têm um importante potencial para despertar a preocupação individual e coletiva para a questão ambiental, contribuindo para o desenvolvimento de reflexões mais críticas, assim, estimulando o enfrentamento de questões ambientais e sociais. Este assunto é abordado em diversas pesquisas sobre parques e UC's no contexto brasileiro (ARAUJO et al., 2015; MOURA et al., 2017; NEIMAN e ADES, 2014; ROCHA et al., 2017; ROCHA et al., 2017; VALENTI, IARED e OLIVEIRA, 2015).

É fundamental que atividades de EA sejam desenvolvidas em diversos setores sociais para que sua abrangência seja maior e se maximize sua efetividade. Nesse contexto, considera-se que "a educação ambiental é um componente essencial e permanente da educação nacional, devendo estar presente, de forma articulada, em todos os níveis e modalidades do processo educativo, em caráter formal e não-formal" (BRASIL, 1999, Art 2º).

Assim, os espaços educativos extraescolares, em especial as UC's, devem ser utilizados para o desenvolvimento de processos de EA, visto que esses locais possibilitam que os indivíduos tenham maior contato com a natureza, podendo ampliar o entendimento da integração do ser humano com a biodiversidade local (COIMBRA e CUNHA, 2006).

Diante disso, o presente estudo teve como objetivo analisar artigos publicados em revistas científicas brasileiras com classificação Qualis A1 e A2 que abordem UC's. A análise dos artigos permitiu identificar as macrorregiões geográficas que mais publicam no Brasil, apontando a evolução temporal de publicações sobre UC's, identificando as temáticas mais abordadas nos trabalhos a partir de suas palavras-chave e quais instituições de fomento se apresentam como principais financiadoras de projetos voltados para essa área. Além disso, 
evidenciou os tipos de instituições (públicas ou privadas) que apresentam maior número de pesquisas sobre o tema e quais as metodologias aplicadas pelos autores dos artigos analisados.

\section{METODOLOGIA}

Para a realização deste estudo foram analisadas revistas brasileiras da área de Ensino dos estratos A1 e A2 disponibilizadas na Plataforma Sucupira de acordo com a última avaliação da Coordenação de Aperfeiçoamento de Pessoal de Nível Superior (CAPES) (2013-2016). Os artigos publicados nessas revistas representam uma importante fonte de dados para estabelecermos um panorama das tendências das pesquisas acadêmicas que estão sendo desenvolvidas sobre Unidades de Conservação no Brasil.

Após a análise preliminar das 343 revistas classificadas como A1 ou A2 pelo Qualis da Capes, foram selecionadas 30 revistas (sendo 14 no estrato A1 e 16 no A2) por se enquadrarem na área de Ensino e apresentarem escopo pertinente aos objetivos deste estudo (relacionado a área ambiental).

Posteriormente a seleção das revistas, buscou-se artigos publicados em todas as edições no período de 2013 a 2017 através das palavras-chave, título e resumo que apresentassem um ou mais dos seguintes termos: parque, trilha, SNUC e Unidade de Conservação. Após o levantamento foram encontrados 16 artigos que passaram a compor a amostragem de análise deste estudo. No quadro abaixo estão apresentados os artigos codificados (P1, P2, P3, etc. - "P" de Paper), os autores e as revistas e ano em que foram publicados.

Quadro 1 - Dados das revistas científicas analisadas.

\begin{tabular}{|c|c|c|}
\hline Código e Título & Autores & $\begin{array}{c}\text { Revista, estrato } \\
\text { Qualis e Ano }\end{array}$ \\
\hline $\begin{array}{l}\text { P1 - O desafio da } \\
\text { conservação de } \\
\text { ambientes aquáticos } \\
\text { e manutenção de } \\
\text { serviços ambientais } \\
\text { em áreas verdes } \\
\text { urbanas: o caso do } \\
\text { Parque Estadual da } \\
\text { Cantareira. }\end{array}$ & $\begin{array}{l}\text { Cassia de Souza de Rares; Ana Lucia } \\
\text { Brandimarte. }\end{array}$ & $\begin{array}{l}\text { Ambiente } \\
\text { Sociedade. A1. } \\
2014 .\end{array}$ \\
\hline $\begin{array}{l}\text { P2 - Gestão e manejo } \\
\text { de áreas naturais } \\
\text { protegidas: contexto } \\
\text { internacional. }\end{array}$ & $\begin{array}{l}\text { Patrícia Costa Pellizzaro; Letícia Peret } \\
\text { Antunes Hardt; Carlos Hardt; Marlon Hardt; } \\
\text { Dyala Assef Sehli. }\end{array}$ & $\begin{array}{l}\text { Ambiente } \\
\text { Sociedade. A1. } \\
2015 .\end{array}$ \\
\hline $\begin{array}{l}\text { P3 - The collective } \\
\text { action on governing } \\
\text { the commons in the } \\
\text { surroundings of } \\
\text { protected areas. }\end{array}$ & $\begin{array}{l}\text { Marcio de Araujo Pereira; Sérgio Schneider; } \\
\text { Jan Douwe Van Der Ploeg; Marcelino de } \\
\text { Souza. }\end{array}$ & $\begin{array}{l}\text { Ambiente } \\
\text { Sociedade. A1. } \\
2016 .\end{array}$ \\
\hline $\begin{array}{l}\text { P4 - Protected areas } \\
\text { and their multiple } \\
\text { territorialities - a } \\
\text { social and }\end{array}$ & $\begin{array}{l}\text { Celia Cristina Clemente Machado; Claudio } \\
\text { Ubiratan Gonçalves; Manuel Bandeira de } \\
\text { Albuquerque; Eugenia C. Pereira. }\end{array}$ & $\begin{array}{l}\text { Ambiente } \\
\text { Sociedade. A1. } \\
2017 .\end{array}$ \\
\hline
\end{tabular}




\begin{tabular}{|c|c|c|}
\hline $\begin{array}{l}\text { environmental } \\
\text { reflection Catimbau } \\
\text { National Park-Brazil. }\end{array}$ & & \\
\hline $\begin{array}{l}\text { P5 - O contato com a } \\
\text { natureza: efeitos de } \\
\text { viagens ao campo } \\
\text { sobre os } \\
\text { conhecimentos } \\
\text { intenções e atitudes } \\
\text { pró-ambientais. }\end{array}$ & Neiman, Zysman; Ades, César. & $\begin{array}{l}\text { Ciência } \quad \text { e } \\
\text { Educação. A1. } \\
2014 .\end{array}$ \\
\hline $\begin{array}{l}\text { P6 - Potencial das } \\
\text { atividades de uso } \\
\text { público do núcleo } \\
\text { Picinguaba do Parque } \\
\text { Estadual da Serra do } \\
\text { Mar (SP) para uma } \\
\text { educação ambiental } \\
\text { crítica. }\end{array}$ & $\begin{array}{l}\text { Valenti, Mayla Willik; Iared, Valéria Ghisloti; } \\
\text { Oliveira, Haydée Torres de }\end{array}$ & $\begin{array}{l}\text { Ciência } \quad \text { e } \\
\text { Educação. A1. } \\
2015 .\end{array}$ \\
\hline $\begin{array}{lr}\text { P7 - } & \text { Trilha } \\
\text { interpretativa como } & \text { com } \\
\text { estratégia } & \text { de } \\
\text { educação em saúde: } \\
\text { potencial para o } \\
\text { trabalho } \\
\begin{array}{l}\text { multiprofissional e } \\
\text { intersetorial. }\end{array}\end{array}$ & $\begin{array}{l}\text { Kleba, Maria } \quad \text { Elisabeth; Colliselli, } \\
\text { Liane; Dutra, Altamir } \\
\text { Eliara Solange. }\end{array}$ & $\begin{array}{l}\text { Interface. A1. } \\
2016 .\end{array}$ \\
\hline $\begin{array}{l}\text { P8 - Cinema e } \\
\text { educação ambiental } \\
\text { no Parque Nacional } \\
\text { da Restinga de } \\
\text { Jurubatiba: reflexões } \\
\text { e práticas } \\
\text { interdisciplinares e } \\
\text { transversais. }\end{array}$ & $\begin{array}{l}\text { Fuentes, Nathalia Moura Muzy; Costa, } \\
\text { Rafael Nogueira; Ruta, Christine }\end{array}$ & $\begin{array}{l}\text { Educação } \quad \& \\
\text { Sociedade. A1. } \\
2016 .\end{array}$ \\
\hline $\begin{array}{l}\text { P9 - Estudos sobre } \\
\text { trilhas: uma análise } \\
\text { de tendências em } \\
\text { eventos de ensino de } \\
\text { ciências e educação } \\
\text { ambiental. }\end{array}$ & $\begin{array}{l}\text { Marcelo Rocha, Roberto Henrique, Carolina } \\
\text { Quitá, Luis Silveira, Victor Vasconcellos }\end{array}$ & $\begin{array}{l}\text { Acta Scientiae. A2. } \\
2016 .\end{array}$ \\
\hline $\begin{array}{l}\text { P10 - Impacto das } \\
\text { mudanças climáticas } \\
\text { naturais e uso } \\
\text { histórico da terra no } \\
\text { desenvolvimento da } \\
\text { paisagem na mata } \\
\text { atlântica do Rio de } \\
\text { Janeiro, Brasil. }\end{array}$ & $\begin{array}{l}\text { Nehren, Udo; Kirchner, André; Sattler, } \\
\text { Dietmar; Turetta, Ana Paula. }\end{array}$ & $\begin{array}{l}\text { Anais da academia } \\
\text { brasileira de } \\
\text { ciências. A2. } \\
2013 .\end{array}$ \\
\hline 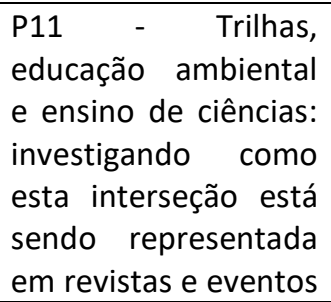 & $\begin{array}{l}\text { Mylena Guedes Passeri, Marcelo Borges } \\
\text { Rocha. }\end{array}$ & $\begin{array}{l}\text { Ensino, Saúde e } \\
\text { Ambiente. A2. } \\
2017\end{array}$ \\
\hline
\end{tabular}




\begin{tabular}{|c|c|c|}
\hline das áreas. & & \\
\hline $\begin{array}{l}\text { P12 - } r \text { Educação } \\
\text { ambiental: } \\
\text { importância das } \\
\text { aulas de campo em } \\
\text { ambientes naturais } \\
\text { para disciplina de } \\
\text { biologia no ensino } \\
\text { médio da escola } \\
\text { Joaquim Parente na } \\
\text { cidade de Bom Jesus } \\
- \text { Pl. }\end{array}$ & $\begin{array}{l}\text { Joniel Mendes de Araujo, Geovania } \\
\text { Figueiredo da Silva, Luciana Barboza Silva, } \\
\text { Gilvan Rodrigues dos Santos, Johnny } \\
\text { Iglesias Mendes Araujo. }\end{array}$ & $\begin{array}{l}\text { Ensino, Saúde e } \\
\text { Ambiente. A2. } \\
2015 .\end{array}$ \\
\hline $\begin{array}{l}\text { P13 - A alfabetização } \\
\text { científica no contexto } \\
\text { da sustentabilidade: } \\
\text { discussão sobre uma } \\
\text { formação de agentes } \\
\text { socioambientais. }\end{array}$ & $\begin{array}{l}\text { Antonio Donizetti Sgarbi, Maria das Graças } \\
\text { Ferreira Lobino, Sabrine Lino Pinto, } \\
\text { Therezinha de Jesus Chanca Lovat, Maria } \\
\text { Luiza de Lima Marques, Wellington Alves } \\
\text { dos Santos. }\end{array}$ & $\begin{array}{l}\text { Praxis. A2. } \\
2015 .\end{array}$ \\
\hline $\begin{array}{l}\text { P14 - O potencial } \\
\text { pedagógico dos } \\
\text { espaços não formais } \\
\text { da cidade de } \\
\text { Manaus. }\end{array}$ & Hiléia Maciel, Augusto Terán & $\begin{array}{l}\text { Areté. A2. } \\
2014 .\end{array}$ \\
\hline $\begin{array}{l}\text { P15 - Aulas de campo } \\
\text { no Parque Estadual } \\
\text { Pedra Azul (ES): } \\
\text { divulgando a ciência } \\
\text { e preservando a } \\
\text { natureza }\end{array}$ & $\begin{array}{l}\text { Celcino Moura, Juliana Conde, Vasty Ferraz, } \\
\text { Carlos Campos. }\end{array}$ & $\begin{array}{l}\text { Areté. A2. } \\
2016 .\end{array}$ \\
\hline $\begin{array}{lr}\text { P16 - } & \text { Educação } \\
\text { infantil e os espaços } \\
\text { não formais: uma } \\
\text { perspectiva } & \text { de } \\
\text { aprendizagem } & \text { no } \\
\text { Parque } & \text { Municipal } \\
\text { Germano } & \text { Augusto } \\
\text { Sampaio em } & \text { Boa } \\
\text { Vista-RR. } & \end{array}$ & $\begin{array}{l}\text { Rosana Chaves, Adriana Vale, Arthur de } \\
\text { Magalhães, Ivanise Rizzatti, Maria Jucileide } \\
\text { Oliveira, Maria Rosângela Sousa. }\end{array}$ & $\begin{array}{l}\text { Areté. A2. } \\
2016 .\end{array}$ \\
\hline
\end{tabular}

Fonte: a pesquisa.

Dessa forma, os artigos foram analisados de acordo com as seguintes categorias: ano de publicação, instituição de ensino de todos os autores, macrorregião geográfica determinada pela origem da instituição estudo do primeiro autor, público/perfil (estudantes de educação básica, graduação e/ou pós-graduação, atores sociais, visitantes em geral, população do entorno e, quando não houve público alvo de investigação, pesquisa bibliográfica), políticas públicas de referência, a metodologia utilizada na pesquisa descrita (trilha/aula de campo, aplicação de questionário e/ou entrevista e pesquisa bibliográfica), o ambiente de coleta (campo prático ou teórico), palavras-chave utilizadas nos artigos e instituições de fomento. 


\section{DESENVOLVIMENTO (RESULTADOS E DISCUSSÕES)}

No gráfico 1 é apresentada a distribuição quantitativa dos artigos analisados tomando por base $o$ ano de suas publicações.

Gráfico 1 - Número de artigos publicados por ano no período de janeiro de 2013 a junho de 2017.

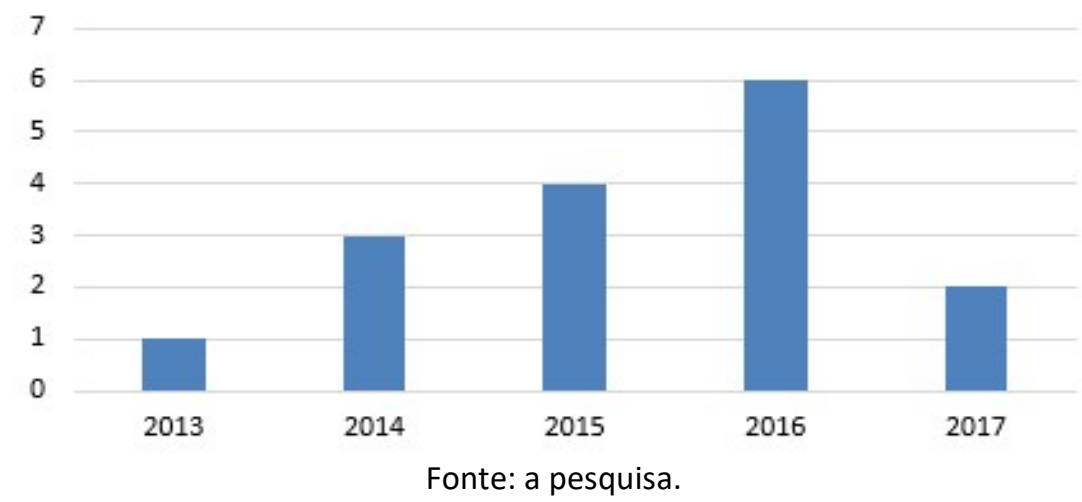

O ano de 2016 destaca-se quantitativamente pelo maior número de publicações, totalizando 06 (seis) artigos. Entendemos que o aumento paulatino de publicações de 2013 a 2016 apresenta uma relação direta com o crescimento do número de Programas de Pós-Graduação no Brasil, incluindo-se aqui os Programas da área de Ensino. Conforme divulgado pelo Ministério da Educação (BRASIL, 2017a, 2017b), a avaliação realizada em Programas de Pós-Graduação pela CAPES constatou que: em 2013 o país apresentava 3.337 programas distribuídos em 5.082 cursos; já em 2017, o país apresentou 4.175 programas distribuídos em 6.303 cursos. Considerando a área de Ensino, a avaliação mostrou que em 2013 havia 92 programas e em 2017 passou a apresentar 157.

Portanto, houve um aumento no número de programas, o que pode ter levado a um maior número de pesquisadores e estudos em diversas áreas (inclusive na área de Ensino), podendo refletir no gradativo crescimento de publicações observado ao longo dos últimos quatro anos.

Apresentamos no quadro 2 o vínculo institucional dos artigos analisados, sendo vinculados a Instituições de Ensino Superior (IES) públicas (federal e estadual), IES privada ou Associações de classe.

Quadro 2 - Vínculo institucional dos periódicos.

\begin{tabular}{|c|c|}
\hline $\begin{array}{c}\text { Vínculo } \\
\text { institucional }\end{array}$ & Periódico (recorrência) \\
\hline IES Pública Federal & Ensino, Saúde e Ambiente (P11, P12); \\
\hline IES Pública Estadual & $\begin{array}{c}\text { Ciência \& Educação (P5, P6, P7); Educação \& Sociedade (P8); } \\
\text { Práxis (P13); Revista Amazônica de Ensino de Ciências (P14, P15, } \\
\text { P16). }\end{array}$ \\
\hline IES Privada & Acta Scientiae (P9). \\
\hline
\end{tabular}




\begin{tabular}{|c|c|}
\hline $\begin{array}{c}\text { Associações de } \\
\text { Classe }\end{array}$ & $\begin{array}{c}\text { Ambiente \& Sociedade (P1, P2, P3, P4); Anais da Academia } \\
\text { Brasileira de Ciências (P10). }\end{array}$ \\
\hline
\end{tabular}

Fonte: a pesquisa.

Conforme é possível observar no quadro 2, a maioria dos artigos publicados está em periódicos vinculados a IES Públicas. Encontramos dois artigos publicados em um periódico vinculado a IES Pública Federal, oito publicados em três periódicos vinculados a IES Pública Estadual, um artigo publicado em periódico vinculado a IES Privada e cinco publicados em Associações de classe que reúnem pesquisadores de áreas de conhecimento específicas.

Dentro do universo pesquisado, os resultados sinalizam a intrínseca relação entre a esfera pública e a disseminação de resultados de pesquisas, o que se constitui, a certo modo, um retorno à sociedade.

No gráfico 2 observa-se as macrorregiões geográficas brasileiras (Norte, Nordeste, Centro-Oeste, Sudeste e Sul) ou além de seus limites (internacional) onde encontram-se vinculados institucionalmente os primeiros autores das publicações analisadas.

Gráfico 2 - Número de artigos por região geográfica de vinculação institucional do primeiro autor.

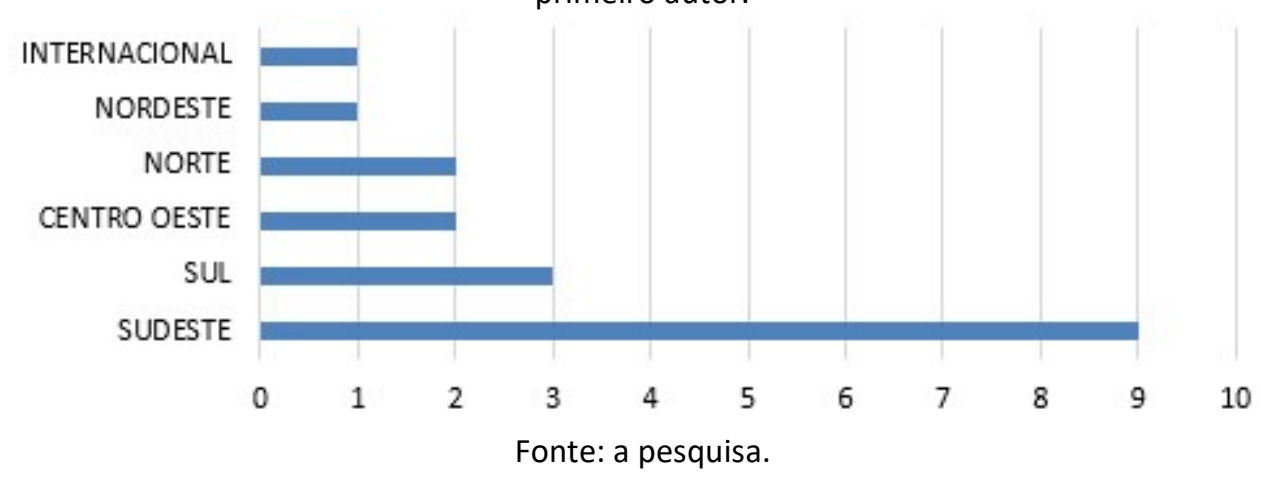

Ao analisarmos o gráfico 2, pode-se notar que a região Sudeste apresenta a maior recorrência de vinculação institucional descrita pelos primeiros autores dos artigos analisados. A região Sudeste com nove autores é seguida da região Sul com três e regiões Norte e Centro-Oeste com dois primeiros autores cada. Esses dados corroboram com o Ministério da Educação (BRASIL, 2017a) no qual a região Sudeste e Sul são apontadas como as duas regiões brasileiras com as maiores quantidades de Programas de Pós-Graduação do país, com respectivamente $44,8 \%$ e $21,2 \%$ dos Programas oficialmente reconhecidos.

Ainda de acordo com o Ministério da Educação (BRASIL, 2017b), as regiões Sudeste e Sul também apresentam uma quantidade maior de Programas na área de Ensino, respectivamente $37,1 \%$ e $26,4 \%$. Em relação à esta situação, percebese a necessidade de uma política diferenciada da CAPES com relação a formação Stricto Sensu nas regiões que menos ofertam Programas na área de Ensino, neste caso, as regiões Norte e Centro-Oeste, uma vez que notadamente a disseminação e os avanços científicos em todas as áreas de conhecimento relacionam-se intimamente ao número e a produção de seus Programas de Pós-Graduação (BRASIL, 2017b). 
Em relação ao público envolvido nas pesquisas da amostra (Gráfico 3), destaca-se que em três artigos (P2; P9; P11) os dados foram estritamente bibliográficos e em um artigo ( $P 10)$ associaram-se a pesquisa bibliográfica e a coleta de dados em campo, não envolvendo amostras com agentes humanos.

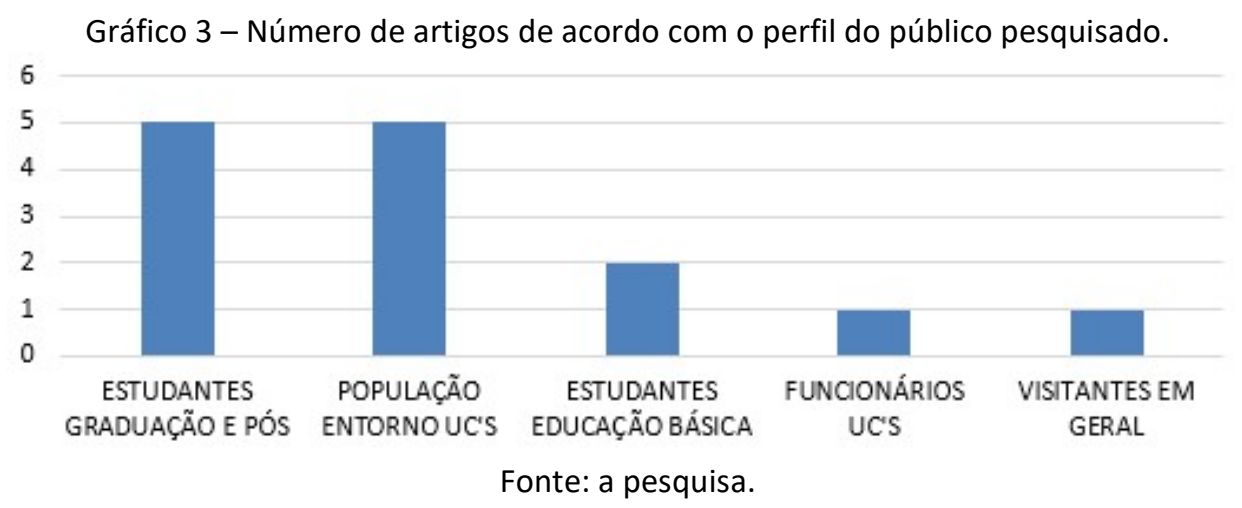

Dentre o perfil do público envolvido nos artigos, a maior quantidade deles trabalhou com Estudantes de Graduação e Pós-Graduação (P5; P6; P7; P8; P15) e População do entorno de UC's (P1; P3, P4; P7; P8), seguidos de trabalhos com Estudantes da Educação Básica (P12; P16), Funcionários de UC's (P14) e público de Visitantes em geral (P13).

As práticas desenvolvidas em UC's acerca da Educação Ambiental colocam em relevância o envolvimento de estudantes e de moradores do entorno, indicando assim que o envolvimento humano por meio da exposição de percepções, concepções, opiniões e expectativas constitui elemento essencial, vivo e subjetivo que significa e corporifica os discursos da Educação Ambiental praticados.

Ao atentarmos para as palavras-chave empregadas nos artigos analisados, encontramos 45 termos distintos. No gráfico 4 apresentamos as dez palavraschave com maior recorrência.

Gráfico 4 - Número de artigos com as palavras-chave de maior recorrência.

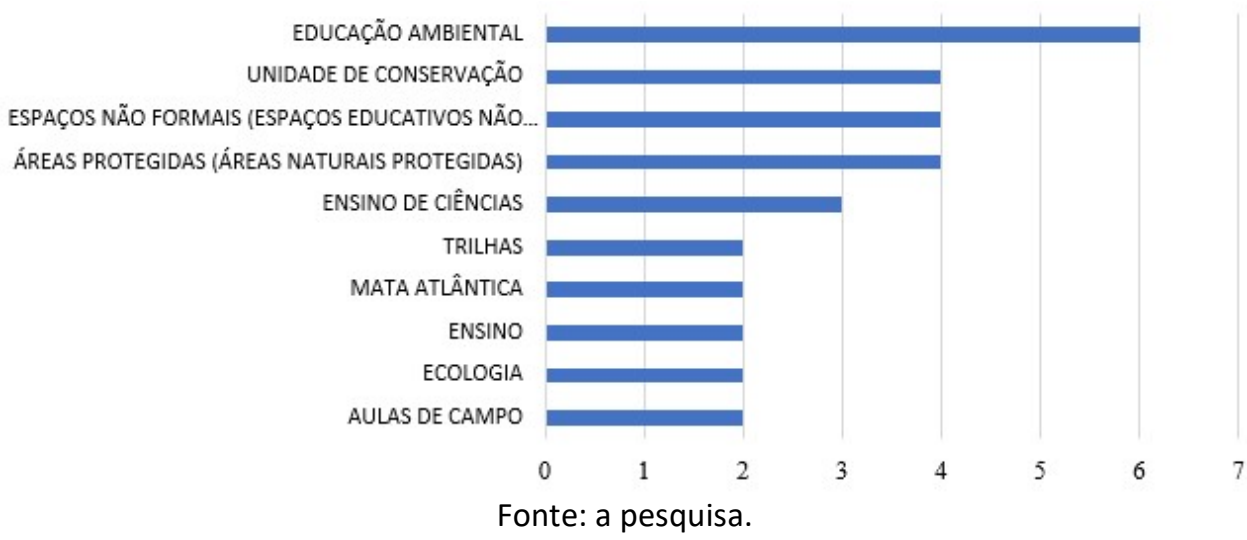

Nota-se que a palavra-chave "Educação Ambiental" foi a mais frequente, constatado em seis dos dezesseis artigos analisados. As palavras-chave "Unidades 
de Conservação", "Espaços Não Formais" e "Áreas Protegidas" também apresentaram uma recorrência significativa, constando cada uma em quatro dos trabalhos analisados. As palavras-chave mais recorrentes vêm ao encontro do mapeamento proposto neste trabalho, pois instituem conectivos afins entre Educação Ambiental em Unidades de Conservação. É lícito destacar, conforme Ercan e Cicekli (2007) e Gonçalves (2008), a importância das palavras-chave em produções acadêmicas, pois além de serem úteis para indexação de pesquisa e categorização de textos, elas também sinalizam a abrangência de um assunto e seus conceitos principais.

Considerando Reigota (1995), Sauvè (1996) e Nardi (2009) a Educação Ambiental deve promover ações, sejam no âmbito da educação formal, não formal e informal, que capacitem os indivíduos a se tornarem sujeitos críticos às questões políticas e ideológicas que cerceiem seu quotidiano. Nesse sentido entendemos que as UC's podem materializar espaços não formais relevantes para a sensibilização tocante aos impactos ambientais decorrentes da ação antrópica, principalmente quando essas ações se desenvolvem impulsionadas por consumo desenfreado e esgotamento dos bens naturais.

No gráfico 5 representa-se a metodologia utilizada no desenvolvimento das pesquisas apresentadas nos artigos analisados.

Gráfico 5 - Número de artigos conforme a metodologia utilizada para o desenvolvimento da pesquisa.

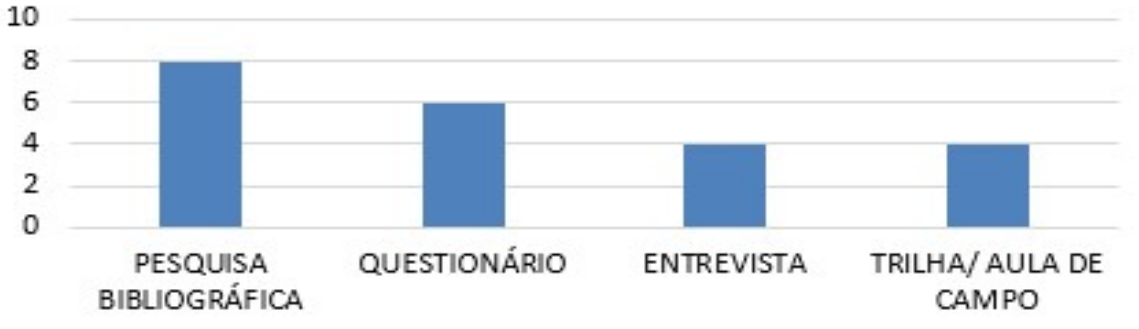

Fonte: a pesquisa.

Conforme sinalizado no gráfico 5 , o método de Pesquisa Bibliográfica se destaca ao apresentar oito recorrências. De acordo com Heerdt e Leonel (2007) pesquisa bibliográfica é aquela que se desenvolve a partir de um tratamento dispendido sobre dados coletados em publicações advindas de diversos tipos: livros, artigos, manuais, enciclopédias, anais, meios eletrônicos, etc. $O$ autor enfatiza que a realização da pesquisa bibliográfica é de grande relevância para a divulgação e a complexificação sobre um determinado tema ou assunto.

Ressalta-se que os trabalhos agrupados em pesquisas bibliográficas não foram complementados por outras metodologias que indiquem a presença do pesquisador na UC, como as idas a campo. Considerando que os artigos analisados têm como objeto de estudo a Educação Ambiental em Unidades de Conservação, o contato com meios naturais abertos extraescolares tem um destaque maior. Nesse sentido, podemos pontuar que os quatro trabalhos que desenvolveram Trilha/Aula de campo, vêm ao encontro de estudos nessas perspectivas. Os espaços naturais in situ por meio de seus centros de visitantes e trilhas ecológicas configuram espaços educativos propícios ao ensino e a pesquisa (MARANDINO et al., 2003). Os trabalhos analisados que apresentam aula de campo, tiveram associado a essa metodologia a aplicação de questionários e entrevistas a fim de coletar dados para posterior análise interpretativa. 
Em todos os trabalhos analisados constatamos uma abordagem qualitativa no tratamento dos dados coletados. Conforme Mello (2001), a abordagem qualitativa marca a interpretação da realidade e não sua quantificação, nesse tipo de abordagem a subjetivação encontrada em inferências, associações e conclusões sobre determinado assunto, como a motivação para o estudo, caracterizam o tratamento. Não se trata apenas quantificar, mas sim de significar aspectos individuais, buscar por detalhes, particularidades e interpretações, que se encontram sobre determinado tema ou situação, na perspectiva do pesquisador.

No gráfico 6 destacamos documentos oficiais utilizados pelos artigos analisados que expressam políticas públicas, sejam de âmbito local, regional, nacional ou global. Vale destacar que foram excluídos os artigos que não se valeram, em seu referencial teórico ou em outra seção do manuscrito, de alguma prescrição oficial sistematizada voltado ao ideário de políticas públicas, neste caso os artigos: P3; P4; P5; P10; P12; P14.

Gráfico 6 - Número de artigos que utilizaram documentos oficiais expressando políticas públicas.

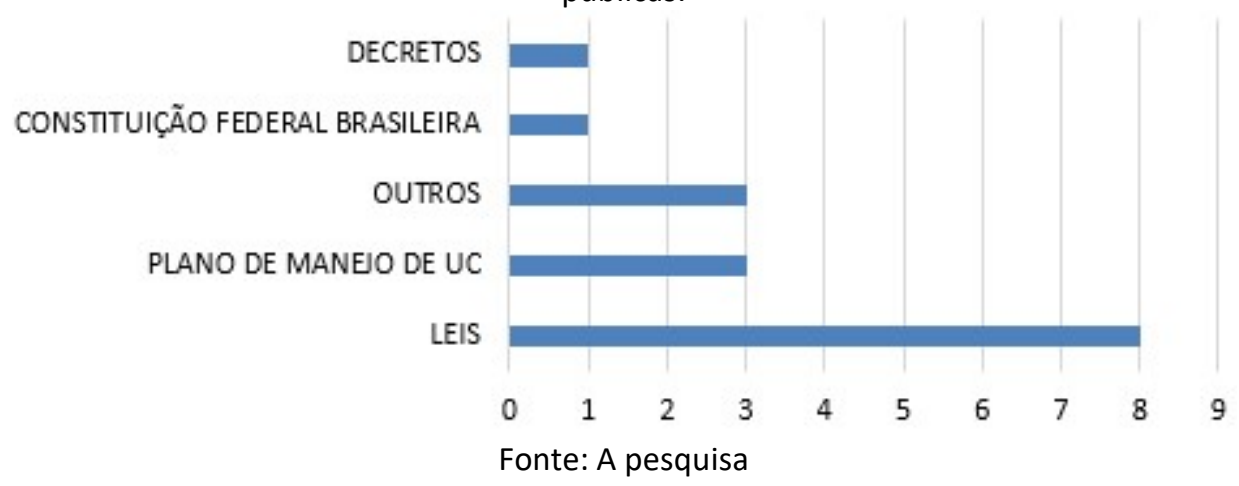

A categorização de Leis, Decretos e Planos de Manejo de UC incorporam prescrições vinculadas ao poder público, sejam em nível federal, estadual ou municipal. Agrupamos no item "Outros" documentos complementares produzidos pelo Poder Público (como por exemplo, os Parâmetros Curriculares Nacionais) e por Organizações colegiadas envolvendo a sociedade civil (como por exemplo, Planos de Bacia Hidrográfica desenvolvidos por seus respectivos comitês).

Vale destacar que dentre as Leis apontadas nos artigos, encontramos maior recorrência à Lei n. 9.795 (BRASIL, 1999) que institui a Política Nacional de Educação Ambiental (PNEA) (presente nos artigos P9; P11; P13) e à Lei n. 9.985 (BRASIL, 2000) que institui o Sistema Nacional de Unidades de Conservação da Natureza - SNUC (presente nos artigos P1. P2 e P15). Pode-se colocar em relevância a interlocução entre essas duas leis, haja vista que explicitamente na Lei n. 9.985 (BRASIL, 2000) preconiza-se favorecer condições e promover a educação, a interpretação ambiental e a recreação em contato com a natureza. Também na Lei n. 9795 (BRASIL, 1999) preconiza-se o incentivo a sensibilização ambiental da sociedade como um todo por parte do Poder Público em todos os seus níveis, com especial atenção as populações tradicionais ligadas às UC's. Nesse sentido, pode-se dizer que desenvolver programas e projetos de Educação Ambiental em UC's, assim como desenvolver pesquisas nesse bojo, coadunam ao 
desenvolvimento de Políticas Públicas voltadas a formação de valores sociais, a preservação e a conservação dos ambientes naturais.

No gráfico 7 apresentamos as instituições explicitadas nos artigos analisados como apoiadores para o desenvolvimento das pesquisas apresentadas. Vale destacar que do corpus documental de dezesseis artigos, sete deles (P5, P11; $\mathrm{P} 12$; $\mathrm{P} 13 ; \mathrm{P} 14, \mathrm{P} 15 ; \mathrm{P} 16)$ não indicaram nenhum tipo de apoio, inclusive institucional.

Gráfico 7 - Número de artigos de acordo com as instituições de apoio às pesquisas.

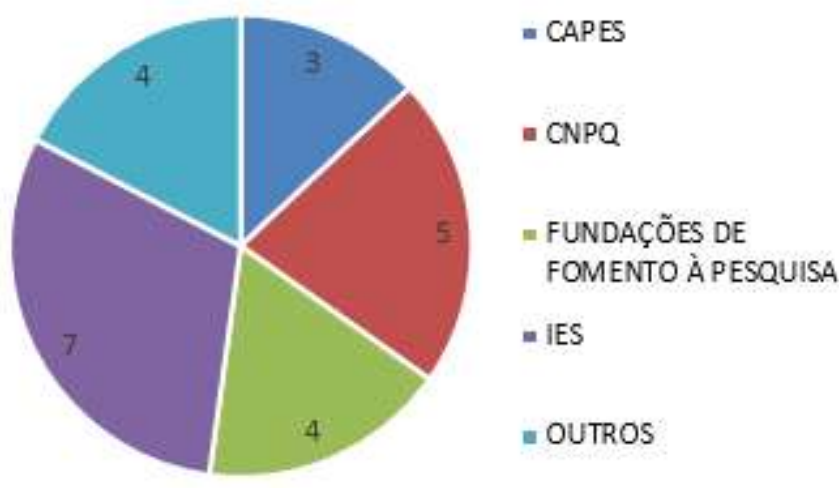

Legenda: CAPES: Coordenação de Aperfeiçoamento de Pessoal de Nível Superior, CNPQ: Conselho Nacional de Desenvolvimento Científico e Tecnológico, IES: Instituições de Ensino Superior.

O apoio a pesquisa segundo Hayashi e Bello (2014) pode ocorrer de diferentes formas: técnico (análises estatísticas, acesso a instrumentos, serviços de laboratório, normalização de documentação, editoração, revisão e elaboração de manuscritos, dentre outros), administrativo (serviços de secretaria, trâmites burocráticos internos e externos), acesso a dados (informações de uso restrito ou confidenciais, materiais experimentais ligados à pesquisa, resultados não publicados, uso de aparelhos e equipamentos específicos), comunicação interativa entre pares (discussão e troca de ideias, comentários críticos, informações específicas, comentários de pares e colegas de pesquisa que atuam como caixas de ressonância e fontes de novas ideias), fomento (subvenções e bolsas recebidas de órgãos, empresas públicas e privadas, instituições, agências), orientação (diretrizes fornecidas pelo orientador e/ou coorientador da pesquisa) e participação da pesquisa (seres humanos, individuais ou em grupos, que participam do processo da pesquisa).

Nesse contexto, tocante aos apoios dados por instituições organizadas encontramos referenciados no gráfico 7 as IES (Instituições de Ensino Superior) em sete artigos, seguidas do Conselho Nacional de Desenvolvimento Científico e Tecnológico (CNPQ) em cinco artigos e de Fundações de apoio à pesquisa (seja em nível estadual - como as citadas Fundação de Amparo à Pesquisa do Estado de São Paulo [FAPESP], Fundação de Amparo à Pesquisa do Estado do Rio de Janeiro [FAPERJ], Fundação Araucária de Apoio ao Desenvolvimento Científico e Tecnológico do Estado do Paraná [FAPPR], Fundação de Apoio ao Desenvolvimento do Ensino, Ciência e Tecnologia do Estado de Mato Grosso do Sul [FUNDECT-MS], seja em nível municipal - como a citada Fundação de Amparo 
à Pesquisa do Município de Macaé) em quatro artigos. Apoios advindos da CAPES são explicitados em três artigos e da categoria outros, que compunham Governos nacional e internacional, em quatro artigos.

Pode-se aferir o quão a pesquisa é um processo multissetorial, pois além do empenho dos pesquisadores envoltos a seus possíveis pares e orientadores, as instituições organizadas têm conspícua importância, principalmente quando por meio de apoios de fomentos subsidiam as condições básicas para que as pesquisas sejam exequíveis.

\section{CONSIDERAÇÕES FINAIS}

As UC's são importantes espaços naturais protegidos, instituídos e fiscalizados pelo poder público, para auxiliar na preservação dos ambientes e se destacam como locais não formais propícios para estratégias de EA. Neste estudo, investigou-se trabalhos publicados em revistas brasileiras classificadas nos estratos A1 e A2 da avaliação da CAPES na área de ensino no período de 2013 a 2017 com intuito de contribuir para o entendimento do estado da arte sobre o tema.

Após o levantamento, dezesseis artigos compuseram a amostra estudada, a maioria foi publicada em 2016 e observa-se um aumento de publicações em períodos recentes quando comparados aos primeiros anos investigados, indicando aumento do interesse e/ou oportunidades de mais estudos.

A esfera pública se destaca como vínculo institucional dos periódicos. Tal resultado é relevante, pois pode refletir maior facilidade de disseminação dos conhecimentos à sociedade.

A macrorregião geográfica que mais possui primeiros autores vinculados é a Sudeste e destaca-se a ocorrência de uma grande diferença em relação às demais regiões brasileiras, o que parece estar de acordo com o número de programas de pós-graduação distribuídos no país. Tais resultados refletem a necessidade de maior estímulo à pesquisa nas regiões com menos publicações, que inclusive abrigam importantes UC's para a preservação e conservação da biodiversidade, por exemplo, a Amazônia Legal. Somente um primeiro autor possui vínculo estrangeiro. Ressalta-se que trabalhos com parcerias institucionais e internacionais poderiam trazer bons frutos ao campo de estudo e à gestão das UC's brasileiras.

O perfil de público mais investigado nos artigos é de estudantes de graduação ou pós-graduação e população do entorno, o que pode refletir a preocupação dos autores em estudar sobre as pessoas que frequentam ou que tem relação direta com a UC. Considerando que "Educação Ambiental" é o termo mais utilizado como palavra-chave, como era esperado, podemos inferir que trabalhos sobre essa temática com estudantes e moradores são de destaque na amostra estudada, enfatizando a importância das UC's como espaços educativos não formais.

A maioria dos trabalhos foi realizada por pesquisas bibliográficas. Enfatiza-se a grande importância de estudos, como este, que buscam entender a partir de materiais já publicados ou documentos a área de estudo. Observam-se, ainda, 
metodologias que, associadas aos demais resultados encontrados e já apresentados, refletem uma maior ocorrência de artigos com foco nas percepções e/ou opiniões de pessoas, como é o caso da aplicação de questionários e entrevistas.

Além disso, a maioria utiliza tratamentos qualitativos para os dados. Isto pode representar uma linha de investigação carente de ser explorada e muito importante para a gestão: tratamentos quantitativos confiáveis e correlacionados com os dados qualitativos.

Destaca-se a importância dos documentos legais como leis, decretos e planos de manejo como relevantes para o embasamento ou análise destes trabalhos. É fundamental que as pesquisas com UC's investiguem se e como esses espaços está ou não de acordo com o enunciado e orientado legalmente.

Representando um dos entraves mais evidentes em certas áreas da pesquisa, percebe-se que sete artigos dos dezesseis analisados não apontam nenhum tipo de apoio, financeiro ou institucional. Mais uma vez, pode-se inferir a carência de parcerias e integração para a pesquisa, no âmbito investigado, sendo uma linha de investigação interessante: por quais motivos tais parcerias, tão importantes em estudos sobre temas multissetoriais como o de UC's, não estão aparecendo nas publicações? Outra questão interessante e pouco explorada nestes artigos é: como se dá a relação de instituições privadas com estudos em UC's? Há interesse e em qual linha investigativa este seria mais observado?

Considerando a urgência e relevância da preservação da biodiversidade e do ambiente como um todo, espera-se que mais estudos e ações possam contribuir para o entendimento e resolução das lacunas aqui apontadas. 


\title{
Studies on conservation units: a survey in brazilian journals.
}

\author{
ABSTRACT
}

Conservation Units are important protected natural spaces that help to preserve the environment and stand out as non formal places conducive to Environmental Education strategies. In this study, articles published in Brazilian journals classified as A1 or A2 by CAPES were investigated in the teaching area, aiming to contribute to the understanding of the state of the art on the subject. The sample studied was sixteen articles. Institutional links in the public sphere were highlighted. The Southeast region is predominant in the number of publications and the low expressiveness of the other regions is worrying. The research preference profile was that of students and residents. There is a certain lack of institutional and private partnerships in the studies investigated. Considering the importance of preserving the environment, it is expected that further studies and actions may contribute to the understanding and resolution of the gaps pointed out in this study.

KEYWORDS: Conservation Unit. Environmental Education. Biodiversity. 


\section{REFERÊNCIAS}

ARAUJO, J. M.; SILVA, G. F. DA; SILVA, L. B.; SANTOS, G. R. DOS; ARAUJO, J. I. M. Educação ambiental: a importância das aulas de campo em ambientes naturais para a disciplina de biologia no ensino médio da escola Joaquim Parente na cidade de Bom Jesus - PI. Revista Ensino, Saúde e Ambiente, v. 8, n. 2, p. 25-36, 2015.

BENSUSAN, N. Conservação da biodiversidade em áreas protegidas. Rio de Janeiro: Editora FGV, 2006. 176p.

BRASIL. Lei n. 9795, de 27 de abril de 1999. Dispõe sobre a educação ambiental, institui a Política Nacional de Educação Ambiental e dá outras providências. Diário Oficial da União. 1999. Disponível em:

<http://www.planalto.gov.br/ccivil_03/leis/19795.htm>. Acesso em: 17 fev. 2018.

BRASIL. Lei n. 9.985, de 18 de julho de 2000. Regulamenta o art. 225, § 10, incisos I, II, III e VII da Constituição Federal, institui o Sistema Nacional de Unidades de Conservação da Natureza e dá outras providências. Diário Oficial da União. 2000. Disponível em: < http://www.planalto.gov.br/ccivil_03/leis/L9985.htm>. Acesso em: 19 de out. 2018.

BRASIL. Ministério da Educação. Avaliação quadrienal em números. 2017a. Disponível em:

<https://docs.google.com/viewer?a=v\&pid=sites\&srcid=Y2FwZXMuZ292LmJyfGF2 YWxpYWNhby1xdWFkcmllbmFsfGd4OjJkZDBjOThhMzAyYzY3ZGI>. Acesso em: 19 out. 2018.

BRASIL. Ministério da Educação. Sobre as Áreas de Avaliação. 2017b. Disponível em: <http://www.capes.gov.br/avaliacao/sobre-as-areas-de-avaliacao>. Acesso em: 17 out. 2018.

COIMBRA, F. G.; CUNHA, A. M. de O. A educação ambiental não formal em unidades de conservação: a experiência do Parque Municipal Vitório Siquierolli. Anais... V Encontro Nacional de Pesquisa em Educação em Ciências, Bauru, SP, Brasil, 2006. ISSN 1809-5100.

CUNHA, A. A.; GUEDES, F. B. Mapeamentos para conservação e recuperação da biodiversidade na Mata Atlântica: em busca de uma estratégia espacial integradora para orientar ações aplicadas. Ministério do Meio Ambiente (MMA), Secretaria de Biodiversidade e Florestas. Brasília, DF. 216p. 2013.

ERCAN, G.: CICEKLI, I. Using lexical chains for keyword extraction. Information processing and management, v. 43, n. 6, p. 1705-1714, 2007.

GONÇALVES, A. L. Uso de resumos e palavras-chave em Ciências Sociais: uma avaliação. Encontros Bibli: Revista Eletrônica de Biblioteconomia e Ciência da Informação, v. 13, n. 26, 2008.

HAYASHI, M. C. P. I.; BELLO, S. F. Presença dos agradecimentos em um periódico da área de Saúde. Revista da Faculdade de Biblioteconomia e Comunicação da UFRGS, v. 20, n. 3, p. 166-193, 2014. 
didático. 5 ed. Palhoça: Unisul Virtual, 2007.

INSTITUTO BRASILEIRO DE GEOGRAFIA E ESTATÍSTICA. Mapa de biomas do Brasil. 2004. Disponível em: <http://mapas.ibge.gov.br/biomas2/viewer.htm>. Acesso em: 19 out. 2018.

KLINK, C. A.; MACHADO, R. B. A conservação do cerrado brasileiro. Megadiversidade, v. 1, n. 1, p. 147-155, 2005.

MACIEL, M. A. Compensação ambiental: instrumento para implementação do Sistema Nacional de Unidades de Conservação. Dissertação (Mestrado em Direito). Centro Universitário de Brasília, 2012.

MARANDINO, M.; SILVEIRA, R. V. M.; CHELINI, M. J.; FERNANDES, A. B.; RACHID, V. A.; MARTINS, L. C.; LOURENÇO, M. F.; FERNANDES, J. A.; FLORENTINO, H. A. A educação não formal e a divulgação cientifica: o que pensa quem faz? Atas... IV Encontro Nacional de Pesquisa em Educação em Ciências, Bauru, SP, Brasil, 2003.

MELLO, L. G. Antropologia cultural: iniciação teorias e temas. 8 ed. São Paulo: Vozes, 2001. $294 \mathrm{p}$.

MOURA, C.; CONDE, J.; FERRAZ, V.; CAMPOS, C. Aulas de campo no Parque Estadual Pedra Azul (ES): divulgando a ciência e preservando a natureza. Revista Areté | Revista Amazônica de Ensino de Ciências, v. 9, n. 19, p. 201-227, 2017. NARDI, R. (Org.). Questões atuais no ensino de ciências. São Paulo: Escrituras, 2009.

NEIMAN, Z.; ADES, C. Contact with nature: effects of field trips on proenvironmental knowledge, intentions and attitudes. Ciênc. Educ., Bauru, SP, v. 20, n. 4, p. 889-902, 2014.

REIGOTA, M. Meio Ambiente e Representação Social. São Paulo: Cortez, 1995. $87 p$.

ROCHA, M.B; PIN, J.R.; GOÉS, Y.B.; RODRIGUES, L.R.L. Contribuições de uma trilha ecológica para as percepções de meio ambiente dos estudantes. Debates em Educação Científica e Tecnológica. v. 7, n. 2, p 19-43, Agosto de 2017.

ROCHA, M.B; PIN, J.R.; GOÉS, Y.B.; RODRIGUES, L.R.L. O potencial das trilhas ecológicas como instrumento de sensibilização ambiental: o caso do Parque Nacional da Tijuca. E-mosaico. v.6, n.12, p. 81-96, 2017.

SAUVÈ, L. Environmental education and sustainable development: a further appraisal. Canadian Journal of Environmental Education, 1, Spring. University of Quebec, Montreal, Canada. v. 1, n. 1, p. 7-34, 1996.

TABARELLI, M.; PINTO, L. P.; SILVA, J. M. C.; HIROTA, M. M.; BEDÊ, L. C. Desafios e oportunidades para a conservação da biodiversidade na Mata Atlântica brasileira. Megadiversidade, v. 1, n. 1, p. 132-138, 2005.

VALENTI, M. W.; IARED, V. G.; OLIVEIRA, H. T. de. Potencial das atividades de uso público do Núcleo Picinguaba do Parque Estadual da Serra do Mar (SP) para uma educação ambiental crítica. Ciênc. Educ., Bauru, SP, v. 21, n. 3, p. 709-724, 2015. 
Recebido: 28 out 2018

Aprovado: 14 abr 2019

DOI: 10.3895/rts.v16n39.8997

Como citar: ROCHA, M.; et.al. Estudos sobre unidades de conservação: um levantamento em periódicos brasileiros. R. Tecnol. Soc., Curitiba, v. 16, n. 39, p. 132-149, jan/mar. 2020

Disponível em: https://periodicos.utfpr.edu.br/rts/article/view/8997. Acesso em: XXX.

Correspondência:

Direito autoral: Este artigo está licenciado sob os termos da Licença Creative Commons-Atribuição 4.0 Internacional. 